\title{
Development of an organic quinoa bar with amaranth and chia
}

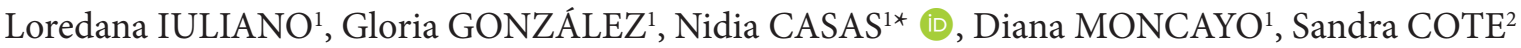

\begin{abstract}
Quinoa is an Andean crop with extraordinary nutritional properties. Its high protein content and well-balanced amino acid composition make it a unique food product for health-conscious consumers. The aim of this study was to develop a cereal bar using organic quinoa with amaranth, chia seeds, nuts and dried fruits. Seven bar prototypes were designed and evaluated in a consumer acceptance test where the attributes flavor, sweetness, texture, and appearance were assessed. The prototype with the highest acceptance scores had the following composition: $9.1 \%$ puffed quinoa; $12.1 \%$ quinoa flake; $6.1 \%$ puffed amaranth; $5.2 \%$ chia seeds; $12.1 \%$ dried cranberry; $15.2 \%$ macadamia nut; $12.1 \%$ sunflower oil; $18.2 \%$ honey; $9.1 \%$ panela; $0.8 \%$ agar-agar. The selected bar was further analyzed in an accelerated stability study over a period of 48 days at three different temperatures. The estimated storage life for each temperature was 35 days at $18{ }^{\circ} \mathrm{C}, 29$ days at $25^{\circ} \mathrm{C}$ and 25 days at $37^{\circ} \mathrm{C}$. Calculations were based on the peroxide value which had been determined as the most critical parameter for the maintenance of the quinoa bar's quality. The developed food product represents an alternative healthy snack with the potential to increase awareness and encourage consumption of quinoa and organic products in Colombia.
\end{abstract}

Keywords: bars; chia seeds; Andean grains; shelf life; peroxide index; texture; consumer acceptance.

Practical Application: Development of a food product with Andean grains and chia seeds that provides a healthy alternative for consumers and increases their awareness and consumption of nutritious products.

\section{Introduction}

Quinoa (Chenopodium quinoa Willd) is a crop of Andean origin that has been grown by various indigenous groups 7.000 years ago and is widely distributed along the Andean highlands (Bhargava \& Srivastava, 2013). The main quinoa producing countries are Bolivia, Peru, and Ecuador. However, in recent years quinoa production has been expanding in different countries of Europe, Asia, Africa, Australia and North America, due to the extraordinary characteristics of adaptation to agro-ecological conditions. Quinoa has a remarkable nutritional quality that is reflected in the high protein content of $13.81 \%$ to $21.9 \%$ depending on the variety (Food and Agriculture Organization of the United Nations, 2011). Also, quinoa provides an ideal balance of fatty acids such as omega 3,6 and 9, fiber, vitamins (B2 and E) and minerals such as calcium and iron (Yumbo, 2014).

Quinoa has been shown to have enormous potential as a transformed food product (Alcocer, 2009; Villacrés et al., 2011). The food industry has developed a considerable number of quinoa-based edible products that are available on the global market. Among these are flours, soups, chips, tortillas, puffed quinoa (quinoa pop) and drinks (Montoya et al., 2005). Despite the wide range of products, consumption is limited to the production countries (Bolivia, Peru, and Ecuador) and the export countries (Europe, USA, and Japan), where the consumption of this ancestral Andean grain has dramatically increased since 2006 (Furchea et al., 2015). In Colombia, the quinoa consumption is still very low due to lack of awareness and scant supply of this grain as a processed product (FAO).

Another trend that has emerged over the last decade is the consumption of organic products, which are commercialized through specialized markets, retail stores and supermarket chains. Consumers have a high perception of the quality of organic food and associate these products with beneficial health effects because they consider the exposure to residual synthetic pesticides and fertilizers, which are present in conventional food, as hazardous (Prieto et al., 2008; Popa et al., 2018). Lairon (2010) concluded that organic agriculture has the potential to produce high-quality products with higher contents of antioxidant micronutrients such as phenols and salicylic acid. Possibly, fertilization practice in organic farming impacts the metabolism of the plant which under stress conditions increases the production of natural defense substances like antioxidants to counteract attacks from insects and pathogens (Faller \& Fialho, 2009).

According to the research company Organic Monitor, the United States is leading the global market for organic food followed by Germany, France, and China. Colombia is the $43^{\text {rd }}$ largest market in the world value. Other than coffee, organic food and beverages are almost non-existent. Thus, to increase awareness and encourage consumption of quinoa and organic products in Colombia. The aim of this study was to develop a commercial bar made of organic quinoa supplemented with 
amaranth and chia seeds, to provide an attractive, healthy food product to Colombian consumers and potentially to improve the value chain of Andean grains for family farmers in Colombia who are seeking for agricultural alternatives.

\section{Materials and methods}

\subsection{Raw material}

Quinoa flakes, puffed quinoa and puffed amaranth and chia seeds were obtained from the company Huertos Verdes. Dried cranberries, grated coconut, almonds, walnuts, macadamia nuts, honey, sunflower oil, water, panela (sugar cane), agar-agar and salt were acquired in different organic and natural food stores in Bogota (Colombia).

\subsection{Experimental design}

Seven bar prototypes were developed using a mixture design that was conceived by first dividing the ingredients into three groups (1. Grains and Seeds: puffed quinoa, quinoa flakes, puffed amaranth, and chia seeds; 2. Nuts and Dried Fruits: almonds, walnuts, macadamia nuts, grated coconut and dried cranberries; 3. Additives: honey, panela, water, sunflower oil, agar-agar and salt) and then combining different proportions of each ingredient group (Table 1).

The proportions used for the design of the seven prototypes had been assessed and optimized in preliminary trials (data not shown) and were set to three fixed values: Minimum (Grains and Seeds 0.31, Nuts and Dried Fruits 0.24, Additives 0.39), Intermediate (Grains and Seeds 0.32, Nuts and Dried Fruits 0.27, Additives 0.40) and Maximum (Grains and Seeds 0.34, Nuts and Dried Fruits 0.31, Additives 0.42).

\subsection{Quinoa bar production process}

Figure 1 shows a flowchart describing the process of quinoa bar production. Initially, dry ingredients (quinoa, amaranth, chia seeds, dried cranberries, nuts and dehydrated grated coconut) were weighed and mixed. In a next step, sunflower oil, panela, water, and salt were mixed and heated up to $70-80{ }^{\circ} \mathrm{C}$ with constant stirring until an elastic mass was obtained. At this point, the dry ingredients were added and mixed thoroughly. The mass was immediately transferred into a mold and cooled down to room temperature. Finally, the bar was removed from the mold, cut into pieces and packed in a metalized packaging film.

\subsection{Consumer acceptance test}

The consumer acceptance test was performed in different health food stores in the north of Bogota where customers were asked to evaluate the sensory characteristics flavor, sweetness, texture, and appearance using a hedonic scale of five levels (Acevedo et al., 2009): 1. I strongly dislike, 2. I dislike, 3. I neither dislike nor like, 4. I like, 5 . I strongly like. The seven bar prototypes were randomly allocated to 3 groups (group 1: P2, P5, P6; group 2: P4, P6, P7; group 3: P1, P3, P4). Each customer evaluated one group with three different prototypes, which were provided in random order. Finally, each group was evaluated by 50 different costumers (67\% female, 33\% male, Age $14-80$ years), a sample size that was
Table 1. Ingredient group proportions used in the mixture design.

\begin{tabular}{cccc}
\hline Prototypes & Grains and Seeds & Nuts and Dried Fruits & Additives \\
\hline P1 & 0.34 & 0.27 & 0.39 \\
P2 & 0.31 & 0.27 & 0.42 \\
P3 & 0.34 & 0.24 & 0.42 \\
P4 & 0.31 & 0.31 & 0.39 \\
P5 & 0.31 & 0.31 & 0.40 \\
P6 & 0.32 & 0.31 & 0.39 \\
P7 & 0.32 & 0.27 & 0.40 \\
\hline
\end{tabular}

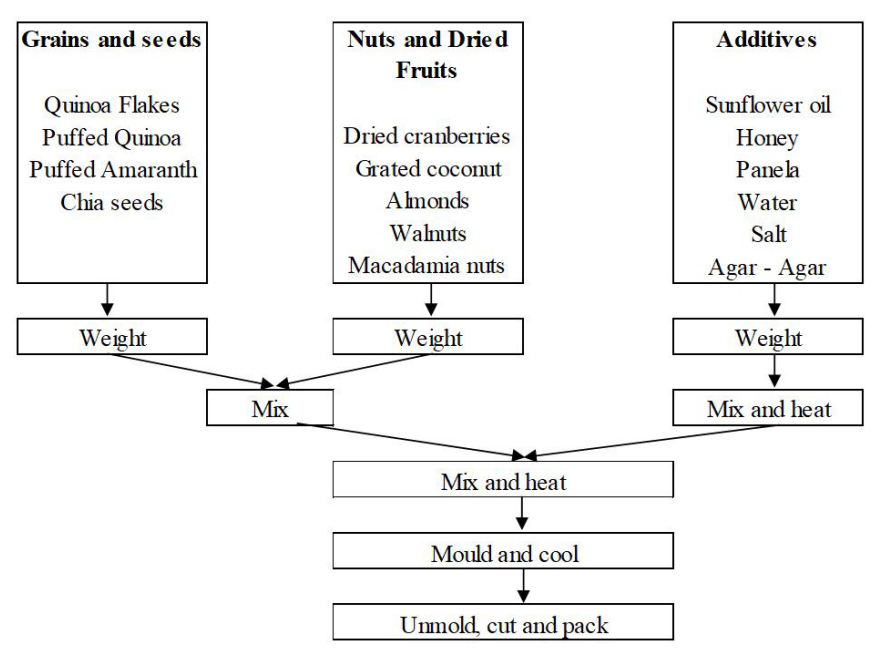

Figure 1. Flowchart for bar production.

defined based on González et al. (2007) considering accuracy of $3 \%$ and an expected proportion of potential customers of $1 \%$.

\subsection{Assessing quinoa bar storage stability}

The shelf life of the quinoa bar was estimated by using an accelerated stability test. The parameters texture, color, peroxide index and sensory property were evaluated over a period of 48 days. Samples were packed in a metallized polypropylene packaging film gauge $90 \mu \mathrm{m}$ with a water transmission equivalent to $<1.0 \mathrm{~g} /\left(\mathrm{m}^{2 \star} 24 \mathrm{~h}^{\star}\right.$ atm $)$ and stored at $18{ }^{\circ} \mathrm{C}, 25^{\circ} \mathrm{C}$ and $37^{\circ} \mathrm{C}$.

\subsection{Texture, color and peroxide index}

Texture and color were measured on day 0, 8, 16, 24, 32, 40 and 48 using a Texture Analyzer Brookfield CT3 ${ }^{\oplus}$ (sample size $5 \mathrm{~mm}$; distance $9 \mathrm{~mm}$; test speed $6 \mathrm{~mm} / \mathrm{s}$ ) and a Colorimeter Konica Minolta - CR100. The peroxide value was determined according to the method AOCS Cd 8-53 (American Oil Chemists Society, 1997) and was measured on the days 0, 24 and 48 .

\subsection{Sensory analysis}

Sensory analysis was performed with a trained panel of 12 judges at the University Uniagraria in Bogota. The attributes color, flavor, aroma, texture and aftertaste were evaluated 
using a hedonic-verbal scale with five levels according to Anzaldúa-Morales (1994).

\subsection{Statistical analysis}

Analysis of variance (ANOVA) and the least significant difference test (LSD) were used to determine statistically significant differences among means $(\mathrm{p}<0.05)$, and nonparametric statistical analysis was performed by applying Friedman's test, with statistical analysis package SPSS version 22 . Also, post hoc analysis with Wilcoxon signed-rank test was conducted with a Bonferroni correction applied, resulting in a significance level set at $p<0.017$. Finally, a correlation study was conducted to determine the correlation coefficients between prototypes and the composition of the quinoa bar.

\section{Results and discussion}

\subsection{Quinoa Bar composition and manufacturing}

Preliminary tests in this study have provided a number of aspects that need to be considered in the process of quinoa bar production. a) The addition of agar-agar to the binding agent mixture must be performed under constant agitation and heating until the desired elasticity is obtained, and favors the agglutination of the bar. b) Panela is unrefined sugar obtained from sugar cane, it supports the solidification process and gives a more rigid texture to the bar. And c) The bar must be cooled down to room temperature before unmolding.

\subsection{Consumer acceptance test}

Seven quinoa bar prototypes were randomly allocated to 3 groups (group 1: P2, P5, P6; group 2: P4, P6, P7; group 3: P1, P3, P4) and evaluated in a consumer acceptance test. Table 2 lists the average scores and standard deviations for each prototype. The best prototypes with the highest overall scores in the individual groups were P6 (group 1), P7 (group 2) and P4 (group 3). There was a statistically significant difference between the prototypes in group 1 as determined by ANOVA regarding texture $(p=0.039)$ and overall score $(p=0.025)$. The Tukey post-hoc test could not detect any statistically significant differences between any prototypes in group 1 regarding the category texture (Table 2), but revealed that the overall score of P2 $(4.01 \pm 1.010)$ was statistically significantly lower $(p=0.021)$ than the overall score of P6 (4.25 \pm 0.799$)$. However, no statistically significant differences were observed between P5 and P2 $(p=0.117)$ nor P5 and P6 $(p=0.646)$. Scores obtained for the quinoa bar prototypes allocated to group 2 and 3 did not differ significantly from each other.

The differences obtained by ANOVA in the category overall score in group 1 were verified in the non-parametric Friedman test (overall score $\chi 2(2)=7.930, p=0.019)$. Post hoc analysis with Wilcoxon signed-rank tests was conducted with a Bonferroni correction applied, resulting in a significance level set at $p<0.017$. The obtained result supports the one obtained in the Tukey test in which a statistically significant difference between $\mathrm{P} 6$ and $\mathrm{P} 2$ in group 1 regarding the overall score could be observed $(Z=-3.285, p=0.001)$.

By analyzing the composition of these two prototypes we observed that P6 contains a higher amount of grains and dried fruits and a lower proportion of additives compared to P2. According to Coleman et al. (2007) the optimal weight/weight proportions of dry ingredients and binder in cereal bars are between 0.7 and 1.5. The weight/weight ratios of the prototypes P6 and P2 lay in the suggested ranges (P6: 1.5; P2:1.4) and seem not differ significantly. The ratio of honey and panela is higher in P6 (ratio = 2) than in P2 (ratio = 1.4). The optimal honey to sugar ratio of poroto (Phaseolus vulgaris L.) and quinoa bars was determined in a study of Calisto (2009). The evaluation was based on the product's texture quality which resulted to be best with a honey to sugar ratio of 0.25 . This value is much lower than the ones observed in our study. Possibly, the higher honey to sugar ratio lead to improved sensory perception of the bar which in turn compensated the potential negative impact on its texture.

Based on the findings in the statistical analysis, P6 was determined as the best quinoa bar prototype in group 1. In group 2 and 3 no statistically significant differences were obtained between the prototypes in any of the evaluated categories. However, we selected the prototypes with the highest overall scores in group $2(\mathrm{P} 7(4.37 \pm 0.72))$ and group $3(\mathrm{P} 4(4.18 \pm 0.93))$ and compared them to P6 of group 1 . The prototype with the highest scores was P7 of group 2 which had the following composition: 9.1\% puffed quinoa; $12.1 \%$ quinoa flake; $6.1 \%$ puffed amaranth; $5.2 \%$ chia seeds; $12.1 \%$ dried cranberry; $15.2 \%$ macadamia nut; $12.1 \%$ sunflower oil; $18.2 \%$ honey; $9.1 \%$ panela; $0.8 \%$ agar-agar. This quinoa bar prototype was selected for further study.

Table 2. Rating averages obtained in the consumer's acceptance test.

\begin{tabular}{|c|c|c|c|c|c|c|}
\hline Group & Prototypes & Flavor & Sweetness & Texture & Appearance & Overall \\
\hline 1 & P6 & $4.24 \pm 0.77$ & $4.10 \pm 0.81$ & $4.20 \pm 0.83$ & $4.44 \pm 0.76$ & $4.25 \pm 0.80$ \\
\hline 1 & $\mathrm{P} 2$ & $4.00 \pm 1.01$ & $3.92 \pm 0.97$ & $3.76 \pm 1.12$ & $4.34 \pm 0.87$ & $4.01 \pm 1.01$ \\
\hline 1 & P5 & $4.10 \pm 0.81$ & $3.96 \pm 0.95$ & $4.18 \pm 0.92$ & $4.42 \pm 0.76$ & $4.17 \pm 0.87$ \\
\hline 2 & P7 & $4.38 \pm 0.67$ & $4.34 \pm 0.77$ & $4.22 \pm 0.86$ & $4.52 \pm 0.54$ & $4.37 \pm 0.72$ \\
\hline 2 & $\mathrm{P} 4$ & $4.24 \pm 0.87$ & $4.04 \pm 0.93$ & $4.48 \pm 0.68$ & $4.46 \pm 0.54$ & $4.31 \pm 0.78$ \\
\hline 2 & P6 & $4.34 \pm 0.92$ & $4.18 \pm 0.96$ & $4.22 \pm 0.95$ & $4.34 \pm 0.85$ & $4.27 \pm 0.92$ \\
\hline 3 & $\mathrm{P} 1$ & $4.06 \pm 1.02$ & $3.94 \pm 1.20$ & $3.98 \pm 1.00$ & $4.12 \pm 0.92$ & $4.03 \pm 1.01$ \\
\hline 3 & P3 & $4.26 \pm 1.01$ & $4.14 \pm 1.05$ & $4.08 \pm 1.01$ & $4.20 \pm 0.86$ & $4.17 \pm 0.98$ \\
\hline 3 & $\mathrm{P} 4$ & $4.24 \pm 0.89$ & $4.06 \pm 1.06$ & $4.12 \pm 0.96$ & $4.28 \pm 0.81$ & $4.18 \pm 0.93$ \\
\hline
\end{tabular}




\subsection{Correlation study}

The statistical relationship between the individual quinoa bar ingredients and the sensory properties was assessed in a correlation study (Table 3). The following correlations were obtained:

1. A higher content of puffed quinoa and quinoa flakes had a negative impact on the appearance of the bar, and to a lesser extent, it negatively influenced the texture and overall score. The addition of puffed amaranth and chia seeds affected the properties appearance, texture and overall score of the bar but in a less pronounced manner than quinoa puffed and quinoa flakes;

2. The addition of macadamia nuts and dried cranberries improved the product taste. Especially, macadamia nuts positively influenced the sense of sweetness, while the dried cranberries contributed to a better texture, sense of sweetness and an overall score of the product. However, an antagonistic effect has been observed between macadamia nuts and additives $(-0.5787)$ such as dried cranberries and additives (-0.5962). Saltos \& Bayas (2010) observed the same effect in energy bars made with bran Pejibaye palm;

3. A higher content of walnuts and almonds adversely affected the flavor and sense of sweetness of the quinoa bar; the latter also reduced the overall sensory value. Garcês et al. (2011) observed similar behavior in their study for cereal bars made with almonds, chicha and nuts sapucaia and Gurguéia. The presence of Gurguéia nuts leads to low acceptability by the panelists, mainly due to the slightly fatty flavor and dark color of this ingredient;

4. There was a middle positive correlation between the addition of sunflower oil, honey, panela and the appearance of the quinoa bar. Honey seemed to further improve the product texture;
5. The panela was added with the intention to improve the texture of the quinoa bar. However, in this case, we only observed a low negative correlation between panela and texture, which was unexpected;

6. The addition of agar-agar had a negative influence on the attributes of flavor, sweetness and texture;

7. The grated coconut was added with the aim to improve the product's flavor. According to the correlation study, the flavor was moderately improved. Further, the perception of sweetness was marginally enhanced while the attribute texture was considerably improved.

The addition of water seemed to have a negative impact on the appearance of the product.

\subsection{Quinoa bar storage stability}

The texture of the quinoa bar P7 (prototype 7) changed over the storage time of 48 days showing a strong decrease of the product toughness in the first 8 days (Table 4 ). After that time point, only minor changes were observed. The color values - $\Delta \mathrm{E}$ measured over storage time showed a random pattern (Table 4). The heterogenic composition of the bar containing ingredients with assorted colors (nuts, dried fruits, etc.,) lead to high variations of the $\Delta \mathrm{E}$ value which did not correlate with storage time.

Sensory evaluation of the quinua bar prototype 7 over storage time did not deliver any statistically significant changes $(\mathrm{p}<0.05)$ for samples that were stored at $18^{\circ} \mathrm{C}$ and $25^{\circ}$ regarding the attributes of flavor, aroma, color and texture. The samples stored at $37^{\circ} \mathrm{C}$ were stable in aroma and color but not in flavor and texture (Table 5). A Tukey post-hoc test revealed that panelists detected a statistically notable change in flavor on day $32,(\mathrm{p}=0.022)$ compared to day 0 , which was mainly caused by the taste of rancidity. Likewise, the texture of the bar had significantly changed after 48 days $(\mathrm{p}=0.048)$, where panelists

Table 3. Correlation analysis between the ingredient groups and sensory properties of seven quinoa bar prototypes evaluated.

\begin{tabular}{|c|c|c|c|c|c|c|}
\hline \multirow{2}{*}{ Ingredient group } & \multirow{2}{*}{ Ingredient } & \multicolumn{5}{|c|}{ Parameter } \\
\hline & & Appearance & Flavor & Sweetness & Texture & Overall \\
\hline \multirow[t]{4}{*}{ Grains and Seeds } & Puffed quinoa & -0.7085 & -0.1943 & -0.1381 & -0.4511 & -0.4308 \\
\hline & Quinoa flakes & -0.7116 & -0.2001 & -0.1419 & -0.4632 & -0.3928 \\
\hline & Puffed amaranth & -0.6864 & -0.1452 & -0.0927 & -0.4225 & -0.3879 \\
\hline & Chia seeds & -0.6766 & -0.1227 & -0.0665 & -0.4391 & -0.3763 \\
\hline \multirow[t]{5}{*}{ Nuts and Dried Fruits } & Dried cranberry & 0.3488 & 0.7735 & 0.6983 & 0.5495 & 0.7043 \\
\hline & Macadamia nut & -0.0844 & 0.7911 & 0.7013 & 0.5564 & 0,5981 \\
\hline & Walnut & 0.3078 & -0.7047 & -0.6148 & -0.5103 & -0.4733 \\
\hline & Almonds & -0.5164 & -0.7939 & -0.7071 & -0.6446 & -0.7874 \\
\hline & Grated coconut & 0.2229 & 0.2930 & 0.1403 & 0.4822 & 0.3421 \\
\hline \multirow[t]{6}{*}{ Additives } & Sunflower oil & 0.4360 & -0.0462 & 0.0285 & -0.3485 & -0.1417 \\
\hline & Water & -0.3873 & 0.1907 & 0.1807 & $5.03 \mathrm{E}-016$ & 0.0074 \\
\hline & Honey & 0.4805 & 0.0805 & -0.0152 & 0.6259 & 0.3486 \\
\hline & Panela & 0.6664 & -0.1960 & -0.1424 & -0.1990 & 0.0113 \\
\hline & Agar-Agar & 0.0220 & -0.4965 & -0.4298 & -0.4159 & -0.4026 \\
\hline & Salt & -0.0306 & 0.1966 & -0.0532 & 0.1733 & 0.0886 \\
\hline
\end{tabular}


Table 4. Texture and color values measured over storage time prototype 7.

\begin{tabular}{|c|c|c|c|c|c|c|}
\hline \multirow{2}{*}{ Days } & \multicolumn{3}{|c|}{ Texture $(\mathrm{gF})$} & \multicolumn{3}{|c|}{ Color $(\Delta \mathrm{E})$} \\
\hline & $18^{\circ} \mathrm{C}$ & $25^{\circ} \mathrm{C}$ & $37^{\circ} \mathrm{C}$ & $18^{\circ} \mathrm{C}$ & $25^{\circ} \mathrm{C}$ & $37^{\circ} \mathrm{C}$ \\
\hline 0 & $2481 \pm 50^{\mathrm{d}}$ & $2481 \pm 50^{\mathrm{d}}$ & $2481 \pm 50^{\mathrm{d}}$ & & & \\
\hline 8 & $799 \pm 62^{\mathrm{bc}}$ & $327 \pm 21^{\mathrm{ab}}$ & $926 \pm 42^{\mathrm{abc}}$ & $3.19 \pm 1.51^{\mathrm{a}}$ & $5.04 \pm 2.31^{\mathrm{a}}$ & $4.03 \pm 1.52^{\mathrm{a}}$ \\
\hline 16 & $975 \pm 14^{c}$ & $884 \pm 12^{c}$ & $1230 \pm 23^{b c}$ & $2.75 \pm 1.24^{\mathrm{a}}$ & $5.25 \pm 0.96^{\mathrm{a}}$ & $5.60 \pm 3.43^{\mathrm{a}}$ \\
\hline 24 & $724 \pm 17^{\mathrm{bc}}$ & $655 \pm 91^{b c}$ & $1092 \pm 16^{\mathrm{abc}}$ & $8.14 \pm 4.88^{\mathrm{a}}$ & $4.83 \pm 2.61^{\mathrm{a}}$ & $5.27 \pm 1.71^{\mathrm{a}}$ \\
\hline 32 & $327 \pm 12^{\mathrm{a}}$ & $418 \pm 13^{\mathrm{ab}}$ & $652 \pm 11^{\mathrm{a}}$ & $7.28 \pm 5.14^{\mathrm{a}}$ & $3.02 \pm 1.10^{\mathrm{a}}$ & $5.08 \pm 1.89^{\mathrm{a}}$ \\
\hline 40 & $409 \pm 19^{\mathrm{ab}}$ & $269 \pm 23^{a}$ & $1280 \pm 37^{c}$ & $5.85 \pm 2.37^{\mathrm{a}}$ & $4.92 \pm 1.11^{\mathrm{a}}$ & $6.12 \pm 3.19^{\mathrm{a}}$ \\
\hline 48 & $466 \pm 14^{\mathrm{ab}}$ & $335 \pm 10^{\mathrm{ab}}$ & $734 \pm 95^{\mathrm{ab}}$ & $4.99 \pm 2.01^{\mathrm{a}}$ & $4.36 \pm 4.02^{\mathrm{a}}$ & $12.91 \pm 3.57^{\mathrm{a}}$ \\
\hline
\end{tabular}

Different letters in the each column indicate significant differences at $\mathrm{p} \leq 0.05$, according to a LDS test.

Table 5. Average scores obtained in the sensory evaluation of the quinoa bar prototype 7.

\begin{tabular}{ccccccccc}
\hline \multirow{2}{*}{ Temperature } & Parameter & \multicolumn{9}{c}{ Days } \\
\cline { 3 - 7 } & & 0 & 8 & 16 & 24 & 32 & 40 \\
\hline \multirow{2}{*}{$18^{\circ} \mathrm{C}$} & Flavor & $4.3 \pm 0.6$ & $3.6 \pm 0.9$ & $3.9 \pm 1.0$ & $4.0 \pm 0.7$ & $3.6 \pm 1.1$ & $3.7 \pm 0.8$ & $4.1 \pm 1.0$ \\
& Aroma & $3.7 \pm 0.9$ & $3.9 \pm 0.8$ & $3.7 \pm 0.6$ & $3.7 \pm 0.9$ & $3.6 \pm 0.8$ & $3.7 \pm 0.9$ & $4.0 \pm 0.8$ \\
& Color & $3.9 \pm 0.7$ & $3.8 \pm 0.6$ & $3.7 \pm 0.8$ & $3.7 \pm 0.7$ & $3.3 \pm 1.0$ & $3.5 \pm 0.8$ & $3.8 \pm 1.0$ \\
& Texture & $3.8 \pm 0.8$ & $3.3 \pm 1.1$ & $3.2 \pm 1.1$ & $3.2 \pm 1.2$ & $2.7 \pm 1.1$ & $3.2 \pm 1.2$ & $3.5 \pm 1.2$ \\
\multirow{3}{*}{$25^{\circ} \mathrm{C}$} & Flavor & $4.3 \pm 0.6$ & $3.6 \pm 1.2$ & $3.6 \pm 1.1$ & $3.7 \pm 0.7$ & $3.7 \pm 0.4$ & $3.5 \pm 1.2$ & $3.6 \pm 0.7$ \\
& Aroma & $3.7 \pm 0.9$ & $3.5 \pm 0.8$ & $3.7 \pm 0.6$ & $3.2 \pm 1.1$ & $3.6 \pm 0.8$ & $3.7 \pm 1.1$ & $3.8 \pm 0.8$ \\
& Color & $3.9 \pm 0.7$ & $3.7 \pm 0.6$ & $3.7 \pm 0.7$ & $3.6 \pm 0.5$ & $3.8 \pm 0.8$ & $3.7 \pm 0.6$ & $3.7 \pm 0.9$ \\
& Texture & $3.8 \pm 0.8$ & $3.2 \pm 0.7$ & $2.6 \pm 1.2$ & $2.6 \pm 0.8$ & $3.3 \pm 1.1$ & $3.1 \pm 1.2$ & $3.3 \pm 1.2$ \\
& Flavor & $4.3 \pm 0.6$ & $4.3 \pm 0.9$ & $3.6 \pm 0.8$ & $3.7 \pm 1.1$ & $3.2 \pm 0.8$ & $3.7 \pm 0.8$ & $3.8 \pm 0.9$ \\
& Aroma & $3.6 \pm 0.9$ & $3.6 \pm 0.7$ & $3.4 \pm 0.9$ & $3.7 \pm 0.89$ & $3.6 \pm 0.8$ & $3.7 \pm 0.8$ & $3.6 \pm 0.7$ \\
& Color & $3.9 \pm 0.7$ & $3.8 \pm 0.6$ & $3.7 \pm 0.6$ & $3.7 \pm 0.8$ & $3.6 \pm 1.0$ & $3.7 \pm 0.6$ & $3.7 \pm 0.6$ \\
& Texture & $3.8 \pm 0.8$ & $3.5 \pm 1.0$ & $3.7 \pm 0.7$ & $3.2 \pm 1.1$ & $3.7 \pm 1.0$ & $3.2 \pm 1.4$ & $2.6 \pm 0.9$ \\
\hline
\end{tabular}

observed a considerable loss of firmness and stickiness of the quinoa bar.

The non-parametric Friedman test confirmed that the difference observed in the attribute flavor was significant $(\mathrm{p}=0.019)$. However the texture of the quinoa bar did not differ significantly $(\mathrm{p}=0.073)$. Post hoc analysis with Wilcoxon signed rank test confirmed the outcome of the Tukey test where a significant difference was in the attribute flavor was observed between day 0 and day $32(\mathrm{p}=0.008)$.

The Codex Alimentarius Commission (CODEX STAN 19-2013) (Codex Alimentarius, 2013) (stipulates a permissible limit of peroxides index in food of $10 \mathrm{meq} \mathrm{O}_{2} / \mathrm{kg}$. In the stability test, the peroxide index of the quinoa bar increased exponentially over storage time and surpassed this limit value after 35 days at all tested storage temperatures (Figure 2). This dramatic drop indicates that the process of lipid oxidation seems to be the most critical parameter for the stability of the quinoa bar. Therefore, this parameter determined the shelf life of the product.

According to Labuza (1984), the order of lipid degradation reaction equals zero. Therefore, the reaction rate constant for each storage temperature was determined by linear regression analysis (Figure 2). The slope of the linear curve (reaction rate constant) describes the changes of the peroxide index over time for each storage temperature. The obtained reaction rate constants were

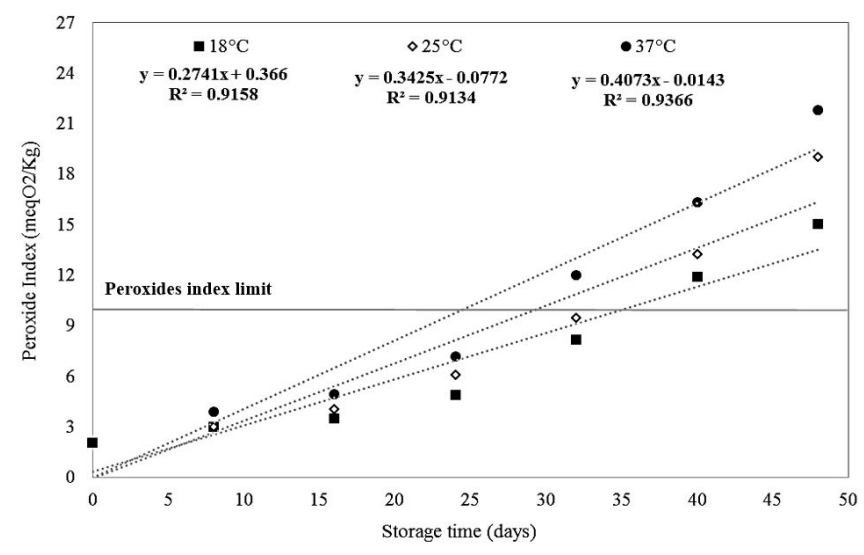

Figure 2. Quinoa bar prototype 7 stability study: Peroxide values measured over storage time.

applied to the Arrhenius model $\ln (\mathrm{k})=\ln \mathrm{A}-(-\mathrm{Ea} / \mathrm{R}) \mathrm{x}(1 / \mathrm{T})$ by graphically displaying $\operatorname{Ln}(\mathrm{k})$ in function of $1 / \mathrm{T}$ which provides the following equation $y=-1830.7 x+5.0223$ with $r^{2}=0.9582$. The activation energy for the lipid oxidation reaction of quinoa bar was calculated by using this equation and gives a value of $15220 \mathrm{~J} / \mathrm{mol}$. According to Rojas et al. (2010) and Torres et al. (2008), the required activation energy for lipid oxidation reactions lies 
between $41840 \mathrm{~J} / \mathrm{mol}$ and $104605 \mathrm{~J} / \mathrm{mol}$. The value obtained in our study is lower than the ones reported.

The shelf life of the quinoa bar was calculated by integrating the permissible limit of peroxides index in food $\left(10\right.$ meq $\left.\mathrm{O}_{2} / \mathrm{kg}\right)$ into the equations obtained in the linear regression in Figure 2. Based on these values, a general equation for the estimation of the product shelf life could be assessed: Shelf life $=10$ exp $\left(1.667-0.0074^{\star} \mathrm{T}^{\circ} \mathrm{C}\right)$. The estimated storage life for each temperature was 35 days at $18{ }^{\circ} \mathrm{C}, 29$ days at $25^{\circ} \mathrm{C}$ and 25 days at $37{ }^{\circ} \mathrm{C}$. Likewise, the $\mathrm{Q}_{10}$ value was also estimated, with a value of 1.2, indicating that reducing storage temperature by $10^{\circ} \mathrm{C}$, the shelf life of the quinoa bar is increased by a factor of 1.2. The shelf life values obtained in this work correlate well with those reported in previous studies where a significant increase of the peroxide value and a decrease of acceptability of cereal bars with nuts were observed after 30 days of storage at $25^{\circ} \mathrm{C}$ (Hernández Arcila, 2011).

\section{Conclusions}

In the present study, we have developed a commercial granola bar with organic quinoa, amaranth and chia seeds that is attractive to the organic food market in Colombia. Different factors affecting the appearance and the organoleptic properties of the bar could be defined. According to the evaluated data, increasing the content of Andean grains in the given proportions seemed to affect the appearance of the quinoa bar. A higher amount of dried cranberries and macadamia nuts improved the flavor while increasing the content of walnuts and almonds had the opposite effect. Most additives had a positive impact on the appearance of the bars when their proportion was increased. Specially, increased amounts of honey seemed to further improve the texture of the quinoa bar while the binding agent agar-agar seemed to negatively influence the attributes flavor, sweetness and texture.

In order to estimate the storage life of the final quinoa bar an accelerated stability test was performed. Out of different parameters tested, the peroxide value was determined as the most critical parameter regarding the quality of the quinoa bar. This observation might be explained by the high content of unsaturated fatty acid present in the ingredients nuts, sunflower oil and chia seeds, components that can lead to the development of oxidative rancidity and therefore to increased peroxide values. There are potential factors that might improve the product's stability and increase its shelf life, one being an optimized packaging that provides an improved barrier to light and oxygen. Further actions might comprise the addition of antioxidants to the product (eg vitamin $\mathrm{C}, \beta$-carotene, magnesium and others) to counteract the oxidation reaction.

\section{Acknowledgements}

The authors acknowledge Huertos Verdes in Subachoque, Cundinamarca and Fundación Universitaria Agraria de ColombiaUNIAGRARIA for the co-financing of this work.

\section{References}

Acevedo, I., García, O., Contreras, J., \& Acevedo, I. (2009). Elaboración y evaluación de las características sensoriales de un yogurt de leche caprina con jalea semifluida de piña. Revista Científica UDO Agrícola, 9(2), 442-448.
Alcocer, E. (2009). Procesos Agroindustriales para 10 productos de quinua - Programa Complejo. Bolivia: Oruro.

American Oil Chemists Society - AOCS. (1997). Official Methods and Recommended Practices of the American Oil Chemists' Society (4th ed., Method Cd 8-53). Champaign: AOCS.

Anzaldúa Morales, A. (1994). La evaluación sensorial de los alimentos en la teoría y la práctica. Zaragoza: Editorial Acribia.

Bhargava, A., \& Srivastava, S. (2013). Quinoa: botany, production and uses. Boston: CABI. http://dx.doi.org/10.1079/9781780642260.0000.

Calisto, L. (2009). Desarrollo de producto snack a base de materias primas no convencionales. Poroto (Phaseolus vulgaris L.) y quinua (Chenopodium quinoa Willd) (Tesis de maestría). Universidad de Chile, Santiago.

Codex Alimentarius. (2013). Codex standard for named vegetable oils (CODEX-STAN 210, Amended 2003-2005). Rome: FAO.

Coleman, E., Schmid, A., Katz, M., \& Birney, S. (2007). U.S. Patent No. 104853. USA: Kraft Foods Holdings, Inc.

Faller, A. L. K., \& Fialho, E. (2009). The antioxidant capacity and polyphenol content of organic and conventional retail vegetables after domestic cooking. Food Research International, 42(1), 210-215. http://dx.doi. org/10.1016/j.foodres.2008.10.009.

Food and Agriculture Organization of the United Nations - FAO. (2011). La quinua: cultivo milenario para contribuir a la seguridad alimentaria mundial. Retrieved from http://www.fao.org/fileadmin/templates/ aiq2013/res/es/cultivo_quinua_es.pdf

Furchea, C., Salcedo, S., Krivonos, E., Rabczuk, P., Jara, B., Fernandez, D., \& Correa, F. (2015). International Quinua trade. In Food and Agriculture Organization of the United Nations - FAO \& French Agricultural Research Centre for International Development - CIRAD. State of the art report on quinoa around the world in 2013 (Chap. 4, pp. 316-329). Rome: FAO/CIRAD.

Garcês, M., Correira, J., Pasos, M., Machado, P., \& Clemente, E. (2011). Formulation and sensory acceptance of cereal-bars made with almonds of chichá, sapucaiaand gurguéia nuts. The Open Food Science Journal, 5, 26-30.

González, J., Paz, J. M., Prieto, B., \& Queraltó, J. (2007). Módulo 2. Determinación del Tamaño Muestral - Curso de estadística para laboratorio clínico. Barcelona: Sociedad Española de Bioquímica Clínica y Patología Molecular.

Hernández Arcila, M. G. (2011). Diseño y formulación de una barra alimenticia a base de frutos secos, avena y miel. (Dissertation master). Universidad Simón Bolívar, Cucutá.

Labuza, T. (1984). Aplication of chemical kinetics to deterioration of foods. Chemical Educator (Boise, Idaho), 61(4), 348-358.

Lairon, D. (2010). Nutritional quality and safety of organic food. A review. Agronomy for Sustainable Development, 30(1), 33-41. http://dx.doi. org/10.1051/agro/2009019.

Montoya, L., Martínez, L., \& Peralta, J. (2005). Análisis de variables estratégicas para la conformación de una cadena productiva de quinua en Colombia. Revista Innovar Journal Revista de Ciencias Administrativas y Sociales, 15(25), 103-119.

Popa, M., Mitelut, A., Popa, E., Stan, A., \& Popa, V. (2018). Organic foods contribution to nutritional quality and value. Trends in Food Science \& Technology. In press. http://dx.doi.org/10.1016/j.tifs.2018.01.003.

Prieto, M., Mouwen, J., Puente, S., \& Sánchez, A. (2008). Concepto de calidad en la industria agroalimentaria. Interciencia, 33(4), 258-264.

Rojas, C., Arteaga, H., Barraza, G., Menedez, E., \& Miano, C. (2010). Estimación de la vida útil de corazones de alcachofa (Cynarascolymus L.) marinados en conserva y el contenido de omega 3 y omega 6. Scientia Agropecuaria, 1, 207-211. 
Saltos, H. Y., \& Bayas, A. (2010). Aplicación de un diseño experimental de mezclas en el desarrollo de una "Barra energética" con base en el salvado de palmito de Pejibaye (Bactrisgasipaes H.B.K.). Revista Tecnológica-ESPOL, 23(2), 1-8.

Torres, E., Pascual, G., Salas, F. (2008). Estabilidad de la bixina soluble en aceite de girasol mediante el uso de pruebas aceleradas de vida útil. Anales Científicos UNALM, 69(4), 65-71.
Villacrés, E., Peralta, E., Egas, L., \& Mazón, N. (2011). Potencial agroindustrial de la quinua (Boletín Divulgativo, No. 146). Quito: Instituto Nacional Autónomo de Investigaciones Agropecuarias/ Imprenta Ideaz.

Yumbo, J. (2014). Elaboración y caracterización de un embutido vegetal a partir de la quinua y habas secas (Tesis de maestría). Universidad de Guayaquil, Guayaquil. 